\title{
INDIVIDUALS, COMMUNITIES, AND GROUPS IN Thomas KuHN's MOdel of SCIENTIFIC DEVELOPMENT
}

\author{
PAULO PIROZELLI \\ Postdoctoral researcher at the Center for Artificial Intelligence (USP), BRAZIL \\ paulo.pirozelli.silva@usp.br
}

\begin{abstract}
In The Structure of Scientific Revolutions, Thomas Kuhn resorts to concepts from several disciplines in order to describe the general patterns of scientific development. This blend of disciplines can be explained in part by Kuhn's intellectual path, from physics to history and then to philosophy of science; but it also points to a deeper methodological problem, which is the question of what is the real unity of analysis in his model of science. The primary intention of this article is, thus, to give a solution to this difficulty. The answer, I believe, rests on identifying three fundamental units present in Kuhn's theory of scientific development. They are, respectively, the individual, responsible for producing evidence, spreading information, and choosing theories; the community, a set of scientists investigating a series of phenomena; and the groups, individuals with similar behavior but with looser institutional or social ties - a usually neglected category in Kuhnian literature, but equally fundamental for the final outcome of scientific debates. After investigating these categories in detail, I propose a way of integrating them into a general model for explaining the resolution of scientific controversies. Finally, I try to resolve the apparent conflict among disciplinary vocabularies by offering an account of the function of sociological, psychological, and epistemological concepts for describing controversies, and some of the methodologies appropriate for each of these tasks.
\end{abstract}

Keywords: Thomas Kuhn • methodological individualism • sociology of science

RECEIVED: $13 / 01 / 2020$

ACCEPTED: 30/10/2020

\section{Introduction}

Thomas Kuhn's The Structure of Scientific Revolutions (1962; from here on, SSR) had a prominent place in twentieth-century philosophy of science. Its marks were widespread and longstanding. They could be seen in the attention received by the book in the years that followed its publication; ${ }^{1}$ the influence of SSR in the debates held on philosophy of science, changing many of questions that had previously shaped the discussions among scholars, ${ }^{2}$ and in the book's enormous repercussions in disciplines other than the philosophy of science - most of all, in the sociology of science, with the rise of the social studies of science. ${ }^{3}$ 
Why SSR was such a milestone has intrigued scholars for a long time. It was probably the right book at the right time: the best exponent of an emerging historicist and naturalist approach to the philosophy of science, at a time when science was ever more prestigious and pervasive to society (Shapin 2015). Whatever the social factors that helped to boost it were, SSR had undeniable intellectual merits too. Particularly, the book gave a broad, (relatively) systematic, and original explanation of how science develops through time. It described the history of science through a pattern of alternating periods of cumulative and non-cumulative research. But instead of the traditional philosophical themes of "development-by-accumulation" and "discovery-of-facts", Kuhn described this complex mechanics through a new set of concepts such as "normal science", "paradigm acquisition", and "scientific revolution" - expressions that he coined (or at least, to which he gave a new meaning) in order to explain the different types of activity to which scientific communities could conform.

His use of original ideas and terms was not restricted to outlining the different kinds of communitarian research, though. In order to explain scientists' actions and choices - particularly, how they respond to anomalies and select theories - Kuhn made use of a distinct set of concepts. These were related to the minds and attitudes of the practitioners of science. Among them, one could find expressions such as "gestalt switch", "change of worldview", and "incommensurability", just to cite the most wellknown.

Still a third group of terms appeared in the book, now related to epistemological issues. These were used to describe the structure of the problems generated by the paradigms, or the possible relations between theories and evidence. The fact that this was a more traditional topic in the philosophy of science did not prevent Kuhn from creating a vocabulary of his own, with his "puzzles" and "anomalies".

The appeal to concepts of so many disciplines could end up blurring the exact nature and aim of Kuhn's project. We may wonder what he was trying to do after all - was he advancing a sociology, a psychology, or a philosophy of science? Or none of these?

A simple explanation for Kuhn's frequent crossing of disciplinary boundaries is that the approach in SSR was essentially transdisciplinary; so, Kuhn had to borrow and mix concepts and methods from distinct disciplines. There is a good amount of truth in that. Kuhn's self-made path from physics to philosophy certainly made his approach more open to influences from different sources, and his ideas more loosely related to previous research (Hufbauer 2012). Biographical issues apart, I do believe that a conceptual difficulty is also responsible for the loose disciplinary affiliation that Kuhn's ideas sometimes seem to take. That deeper methodological problem comes from the fact that it is not immediately clear who (or what) is the subject of the explanations he gives. 
The first two categories that can be found in SSR are the individual and the community. As Kuhn later acknowledged, his original discussion often conflated these, treating "groups as individuals writ large or else individuals as groups writ small" (1993, p. 241; see also 1991 ; 1993) — a serious categorical mistake that misrepresented the process of conceptual change. A good example of that was the analogy between scientific revolutions and gestalt changes. ${ }^{4}$ Next to individuals and communities, it is also possible to identify a third category in SSR. It is what I call groups individuals in the community who have a similar appreciation of theories.

The first part of this article investigates the nature and function of the three different categories that can be found in Kuhn's philosophy of science. Next, I propose a way of integrating individuals, communities, and groups into a general explanatory model for understanding scientific controversies. Finally, I discuss the function of sociological, psychological, and epistemological concepts for this explanatory model, and some of the methods that could be helpful for each kind of investigation.

\section{Individuals, Communities, and Groups}

Individual scientists constitute a core element in Kuhn's model of scientific development. They are responsible for producing evidence, testing hypotheses, exchanging information, socializing new members, and choosing theories. Ultimately, individuals are the only real agents in Kuhn's model of scientific development (Pirozelli 2019).

The importance attributed to singular agents connects Kuhn's approach to an individualistic stance. The question, then, is what kind of individualism that would be. According to Sawyer (2002), individualism may be of two kinds, depending on whether it makes ontological or methodological claims:

Ontological individualism is the stance that only individuals exist; sociological objects and properties are nothing but combinations of the individual participants and their properties. Methodological individualism is an epistemological stance that argues that every event that sociology explains can be explained in terms of individuals, and every law in sociology can be explained by laws concerning individuals (p.537).

There is no doubt that Kuhn endorsed some form of ontological individualism. He claimed, for instance, that groups have no mind and make no decisions (Kuhn 1993). The more complicated question is whether he accepted (or should have accepted) methodological individualism; the assumption that "all social phenomena - their structure and their change - are in principle explicable in ways that only involve individuals - their properties, their goals, their beliefs, and their actions" (Elster 1985, p.5). 
As far as I know, we cannot find an explicit acceptance or rejection of methodological individualism in Kuhn's writings. While he claims that communities do not have interests or make decisions (Kuhn 1993, p.242), he also states that communities are "the primary unit through which the sciences develop" (Kuhn 1991, p.103). For me, no conclusion regarding Kuhn's methodological individualism can be extracted from his scarce observations on the role of individuals and communities in science.

It would be tempting to assume that, since Kuhn endorses ontological individualism, he would have to accept methodological individualism; that, although he did not assume any position on the matter, he would inevitably be led to methodological individualism. Given that only individuals exist, we could think, explanations must involve individuals only.

However, as Sawyer (2002) and Kincaid (1986) argue, ontological individualism does not imply methodological individualism. Social events could be realizable in multiple ways in relationships among individuals, meaning that "no single type of the configuration of individuals and their interactions corresponds to the predicates of a social theory" (Mitrović 2017). Thus, the fact that Kuhn assumes ontological individualism does not allow us to conclude that he supported, or should have supported, a methodological individualist position (or that methodological individualism represented the only consistent position to his ontological individualism).

Were Kuhn not a methodological individualist, no problem would arise in talking about individuals and communities simultaneously. The two entities would obviously have very different functions in his descriptions - the individual being the physical agent and the community being the explanatory unit for sociological purposes. No conflict would arise in between the role of individuals and communities individuals would have their ontological status, while communities would still have a methodological function. ${ }^{5}$ But what would happen if Kuhn were a methodological individualist? One could, then, think that the role attributed to individuals would be incompatible with a focus on communities.

I want to show that even if we assume a strictly methodological and individualist stance in Kuhn's work, there is a reasonable interpretation in which communities still have a place. In this case, the notion of "community" must be understood in a reductionist way, meaning that references to communities can always be re-written in terms of descriptions of individual scientists. "Community", in this sense, is no more than an abbreviation for "multiple individuals in interaction". Instead of saying that a community accepts a theory $T$, we could in principle say that scientists $s_{1}, s_{2}, s_{3} \ldots$ accept theory $T$. In that case, all talk of communities as agents of scientific development would be necessarily metaphorical. I will refer to this reductionist sense of "community" as community $r$.

Community $r$ can have a role in explaining scientific development because methodological individualism does not imply methodological solipsism — "the traditional 
view of science as, at least in principle, a one-person game" (Kuhn 1993, p.243). In other words, even if we restrict the analysis of science to individuals, that does not mean that agents should be considered in isolation. For Kuhn, a proper account of scientific development needs to consider the interactions among multiple "intercommunicating specialists" (1991, p.98).

Attention to multiple scientists in interaction, community $r$, is necessary for three main reasons in Kuhn's model of scientific development. In the first place, scientists' identities are shaped through social relations, particularly through education and socialization (1993, p.242). It is the interaction among individuals that allows the transmission of the cognitive and behavioral components necessary to scientific practice, such as theories, values, and vocabulary; the distribution of epistemic efforts, through cooperation and dispute; and the spreading of information and knowledge; among other things.

The second reason why reference to community $r$ is essential lies in explaining consensus formation. According to Kuhn, scientists share a set of epistemic criteria for evaluating and choosing theories, such as accuracy, consistency, scope, simplicity, and fruitfulness. However, by virtue of the differences in scientists' personal and professional backgrounds, the concrete application of these criteria may differ from person to person. As a consequence of that, "two men fully committed to the same list of criteria for choice may nevertheless reach different conclusions" (1977, p.324).

Scientific consensus, therefore, cannot be explained through a set of universal and precise rules. Instead, it originates, for Kuhn, from specific social mechanisms capable of producing rational agreement in the face of the divergent application of values (Kuhn 1962, ch.12; see also Wray 2011, Part II; D'Agostino 2010). The first social mechanism is scientific pedagogy, which is responsible for the transmission of values and, indirectly, for circumscribing the disagreement of evaluation among scientists (Mody \& Kaiser 2008). The second is what D'Agostino (2010) calls the "wave-theory". By working with a theory, scientists may bolster its achievements, converting more followers to it, in a process that generates a progressive regimentation. In principle, this movement could grow until absolute conformity to the new theory is attained; controversies, however, rarely end up in the unanimous acceptance of scientists. More often (if not always), some of the scientists remain unconvinced, despite the numerous arguments and evidence developed in the exchange. In this case, what happens is a restructuring of the scientific field. This may happen in two ways: with the formation of new specialties (Kuhn 1991; 1992) or with the marginalization of resistant members (Kuhn 1962, p.158).

The last reason that explains the importance of community $r$ is that scientists' actions always happen within a specific social context and are bound by institutional constraints (Jarvie 1998). It is easy to forget this, because the social context is often presupposed in explanations, and we tend to restrict our attention to the individual 
characteristics, not to the agent's situation (D'Agostino 2019b). Nonetheless, we have to keep in mind, particularly when dealing with such a highly social activity as science, the importance of the "workings of the institutions in which knowledge claims are developed and tested" (D'Agostino 2019a, p.2).

This is what explains why Kuhn would still be concerned with communities and communitarian patterns of activity even if he held a methodological individualist position. In order to understand how knowledge is produced, it is essential to consider how scientists make decisions in specific social contexts, interact with one another, and change their evaluations as a consequence of that. As Kuhn explains, "though the units which exchange those statements are individual scientists, understanding the advance of knowledge, the outcome of their practice, depends upon seeing them as atoms constitutive of a larger whole, the community of practitioners of some scientific specialty" (1991, p.103; see also 1962, p.152). There is, in this sense, a "primacy of the community over its members" (1991, p.104).

In sum, the first two categories that can be found in Kuhn's writings are the individual and the community: the former being the agent that actually exists and acts, and the latter, a category used for explanatory purposes (whether or not it has an ontological status). ${ }^{6}$

The third element in Kuhn's model of scientific development is the group - a category that refers to multiple individuals, but is not synonymous with communities. Kuhn does not refer to groups explicitly, but we can infer their role from his remarks on epistemic values and from his comments on scientific controversies.

As stated before, for Kuhn, the evaluation formulas used by scientists vary from individual to individual due to differences in personality and education. This, however, does not exclude the possibility of some homogeneity in the way groups of scientists evaluate theories at a given moment. In fact, for Kuhn, it is expected that some members of a community have similar formulas of evaluation. This is a natural consequence of the way values are acquired. If personal and professional experiences shape the way scientists evaluate theories, then scientists who have undergone similar influences should possess similar evaluation formulas.

That can be put in a more formal frame. If the cause of scientist $X$ having the evaluation formula $f_{X}$ is a factor $\alpha \in A$, where $A$ is the set of all the factors that influence the acquisition and interpretation of epistemic values, and if scientist $Y$ is also subject to $\alpha$, then $f_{Y}$ must resemble $f_{X}$ in some manner. At the limit, if $A$ is the same for $X$ and $Y, f_{X}$ and $f_{Y}$ must be the same. Obviously, it is impossible for any two scientists to have passed through exactly the same experiences. But we can reason that the closer scientists' experiences are, the higher the similarity in their evaluation formulas will be, and, similarly, that the differences in the way they evaluate theories are due to the distinct causal processes they have gone through - i.e., factors they did not share in their formative paths. Therefore, if certain scientists are subject 
to analogous conditions of education and socialization, one would expect them to choose theories for the same reasons when given the same body of evidence.

Another evidence of the existence of the groups in Kuhn's analyses comes from his descriptions in the history of science, particularly those on scientific controversies. He claims that the background of scientists may explain their position in those episodes. For example, younger scientists would tend to value novelty, whereas more experienced members would be more resistant to change - which became known as Planck's principle (1962, ch. 12). ${ }^{7}$ Kuhn also says that "scientists who share the concerns and sensibilities of the individual who discovers a new theory are ipso facto likely to appear disproportionately frequently among that theory's first supporters" (1977, p.328; see also 1962, p.154). Indeed, it is only because scientists may disagree on how to evaluate theories that controversies can arise and new approaches can be explored and developed.

Let us see now how we can differentiate each of the three categories found in SSR — individuals, groups, and communities. In a reductionist interpretation, individuals can be distinguished from both communities and groups, because they are the only agents who are, in a strong sense, real; whereas communities and groups are only analytical units - i.e., conceptual generalizations that we use for explanatory purposes, but which do not exist apart from that. ${ }^{8}$ The difference in between groups and communities is harder to define, but we can say that communities have a more solid social and institutional character. At least, this is how Kuhn characterizes them in the Postscript to SSR (1970).

In the Postscript, Kuhn defines a community as the "the practitioners of a scientific specialty". Those are people who have "undergone similar educations and professional initiations", and in that process "absorbed the same technical literature and drawn many of the same lessons from it". Kuhn suggests that to identify these communities, one can look at things as the "subject of highest degree, membership in professional societies, and journals read". In case of smaller or still not fully-formed communities, he says that one could also pay attention "to attendance at special conferences, to the distribution of draft manuscripts or galley proofs prior to publication, and above all to formal and informal communication networks including those discovered in correspondence and in the linkages among citation" (1970, p.177).

Contrary to communities, groups would be looser sets of scientists who share some preferences, but do not necessarily constitute independent, sociologically identifiable clusters. Groups would be generalizations regarding scientists' preference and behavior which account for the differences in adhesion to a theory. To illustrate with an extensively discussed example given in $S S R$, we can say that, within the community of chemists of the eighteenth-century, there were many several groups - those who endorsed phlosgitonians principles, those who rejected it, those with an experimentalist bent, those with a more analytic approach, etc. 
The line between communities and groups, of course, is highly artificial, since social elements are often connected to theoretical preferences. Even the delimitation of communities, which I said are more institutionalized in nature than groups, tends to be relatively arbitrary. To use again the same example, in the eighteenth century, chemistry and physics were not clearly two independent disciplines. Indeed, the specific nature of chemistry was one the main points of disagreement among scientists at the time (Golinski 2008).

Considering a set of scientists as a community always depends on methodological and theoretical compromises as regards the intensity of their communications and interactions, their relative autonomy as to other scientists, among other things. Moreover, groups sometimes grow to become independent communities, and in the meantime we may disagree on how to treat them. Thus, depending on how we tried to explain the chemical revolution, we could treat the analytic chemists as a subcommunity of chemistry - having certain institutional roles and social ties, as the many members of academia in France - , or as a group inside the proper community of chemists - a group that gave a high value to precise measurements involving the weight of substances, among other things.

In summary, Kuhn's model of scientific development contemplates three categories: the individual scientist, the agent that has a proper existence and that performs all the actions; the community, a set of individuals - identified by social and institutional features - who are in charge of investigating a number of problems; and the group, a set of individuals with similar preferences and behaviors, who are part of a more formal community (Figure 1).

\section{An Explanatory Model of Scientific Development}

The previous section was devoted to exploring the different categories in Kuhn's analysis of science. Although Kuhn did not discuss those issues in depth - particularly, those concerning groups - I I believe these units could be fairly distinguished in the explanations he gave of scientific development.

Now I wish to go a step further and consider how individuals, communities, and groups can be integrated into a broader explanatory model. Although I believe this explanatory model to be close in "spirit" to Kuhn's approach, especially by having these three different categories as a constitutive element, this is not supposed to be an interpretative exercise on his thought.

For practical matters, my explanation will be restricted to a single stage of scientific development, that of theoretical controversies. The reason for choosing that topic is twofold. First, controversies are the founding element of Kuhn's sociological approach, provided that individual criteria of rationality are not sufficient to explain 


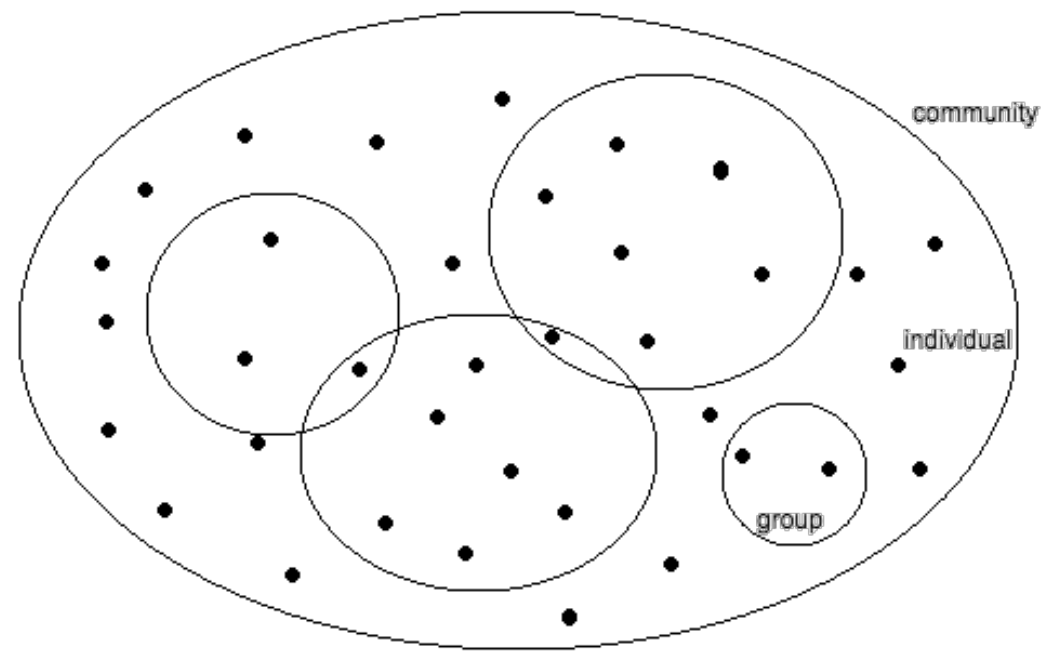

Figure 1: Figure 1 - Communities, individuals, and groups.

consensus formation (Kuhn, 1977; see also D'agostino, 2010; Pirozelli, 2019) — so, this proposal can be directly compared to Kuhn's own remarks on the subject. More importantly, controversies are an immensely rich subject, one in which theories, evidence, and social interactions are all intertwined; thus, the way we describe the acceptance of new theories has a direct impact on our conception of science itself. Although inevitably partial, I think that can give us a good glimpse of the structure that explanations of scientific development could take in general.

We can start by considering what is the object of that explanatory model. Briefly, we want to explain why some scientists, who used to accept a theory $T_{1}$, came to accept another theory $T_{2}$. What I want to see now is the role that individuals, communities, and groups could have in answering these questions. ${ }^{9}$

We can think that this larger problem - why a new theory replaces an older one - encompasses a number of smaller questions, such as:

1. What was the controversy?

2. Who participated in it?

3. What theories were in dispute?

4. What theories did individuals adopt at each moment?

5. How much agreement was there among scientists?

6. What considerations determined their choices?

7. Did some groups of scientists adopt the theory for similar reasons? 
8. What was the cause of these evaluation formulas within these groups?

9. How was consensus created?

10. What was the new configuration of the community?

These questions should not be taken very strictly. Their function is only to highlight the aspects we should pay attention to when explaining why a new scientific theory was accepted. Now, let me propose a way to address these questions that makes reference to individuals, communities, and groups. In answering them, we would have something with the following structure:

1. Electing a scientific controversy of study.

2. Circumscribing the scientists (the community, in a reductionist sense) participating in the controversy.

3. Determining the theories in dispute.

4. Distinguishing the theoretical choices of the scientists at the beginning of the controversy and in the subsequent moments until the disagreement comes to an end, and mapping the flows of adhesion and resistance to the new theory.

5. Measuring the levels of consensus within the community during the various periods of the controversy, in order to determine the stages of the scientific debate.

6. Identifying the motivations underlying scientists' theoretical choices: epistemic values, expectations about the future achievements of theories, etc.

7. Correlating the moment of acceptance of a theory (point 5) with certain evaluation criteria (point 6), consequently highlighting groups of similar behavior.

8. Pointing out the conditions that cause the similar preferences in evaluations in these groups. 9. Describing the mechanisms that promote the production and maintenance of consensus and dissent in the community analyzed.

10. Determining the new communitarian configurations (revolution, speciation, superposition) and relative degrees of consensus in each of them.

Despite its arbitrary character, this list of problems, hopefully, exemplifies the different sorts of elements that are involved in the explanation of a scientific controversy.

The first aspect is exactly in relation to the types of entities that can be considered - individuals, communities, and groups. One set of questions (points 2, 3, 5, 9 and 10) corresponds to the description of the community involved in the controversy: the constituent members, the theories in dispute, the supporters on each side, the level of consensus, the mechanisms that made the consensus to change, and the final configuration of the community. 
A second group of problems refers to individuals (points 4 and 6). The objective here is to understand the theories accepted by them, as well as the cognitive and psychological aspects associated with their choices. Why did a scientist choose a certain theory at a particular moment?

Finally, there is a set of problems related to the group level (points 7 and 8), concerning the existence of groups of similar behavior who would have accepted a theory at the same time and for the same reasons. What made certain evaluative components more relevant to these particular groups of scientists? Is it possible to correlate these components with specific factors (institutional position, age, field of study, etc.)?

The second main feature of this explanatory model is related to the kinds of concepts employed. This was the problem with which this article began. There, I mentioned the tension among three sorts of concepts in Kuhn's writings - sociological, psychological, and epistemological concepts. Now we can see the appropriate place for each of them.

Questions about communities, as we could expect, involve sociological concepts. The main problem we want to explain has to do with changes in the acceptance of theories within communities, transitions in consensus and dissensus. Sociological concepts, then, serve to explain a community's configurations and the mechanisms that produce consensus within it.

The place of psychological and epistemological concepts depends on understanding the role of values in theory-choice. If we want to explain why scientists should have chosen certain theories, given their specific appreciations of values, then the answer to that question needs to make use of epistemic concepts, as the quality of a puzzle-solution and the difficulties posed by anomalies to a theory. That is a matter of justification (or normative reason), and it is framed in epistemological terms. Since the interpretation of values is always the result of idiosyncratic factors, this type of explanation is most appropriate to questions about individual practices - although it could be used, somewhat, as an empirical generalization about the behavior of sets of scientists.

On the other hand, if we want to understand why scientists endorsed values in a certain way or what led them to choose a certain theory, then we are dealing with matters of motivations or explanations (Alvarez 2018). A motivating reason is a reason that favors an action from the person's perspective. They are reasons that lead a scientist to actually choose a theory (for which they may have a justification or not). Motivations are always related to individuals, since only individuals are endowed and may act intentionally. At most, they can be used to refer to groups or communities in a secondary sense, similarly to normative reasons.

Explanatory reasons, in turn, are reasons that explain an action but which do not necessarily involve a normative or motivating reason. Although we can give explana- 
tory reasons for individual behaviors, those are more properly adequate to groups than to individuals or communities. By definition, it is not possible to establish the effect of a cause for individual cases, since the establishment of causal effects presuppose the comparison between a real state and a counterfactual state. It is possible, however, to estimate the causal effect of a feature for a random variable. In that case, the causal effect is simply "the difference between the systematic component of observations made when the explanatory variable takes a value, and the systematic component of comparable observations when the explanatory variable takes another value" (King et al., 1994, pp.81-2; see also Morgan \& Winship 2015).

In this way, we can measure the causal effect of different factors that account for the evaluations of a theory in a community, by considering different treatment and control groups - individuals who possess some feature and individuals who do not. This possibility makes groups a key piece in explaining the causes of individuals' assessments of theories. Groups allow one to measure the causal effect of certain factors on the appreciation of theories within an apparently homogenous community. That is why they are so important to an explanatory model of scientific controversies.

These causal factors can be of many different types. In SSR, Kuhn employed psychological and sociological concepts to explain scientists' appreciations of theories, but other types of concepts could also have been used, such as those from economics or political science (except for epistemological terms, since these deal with justifications). Ultimately, they have all the same purpose: to explain differences in the preferences of scientists, which account for their positions in the controversies.

\section{Methodological issues}

In the previous section, I proposed a general way of explaining the development of a scientific controversy. One of the things that motivated that attempt was trying to understand the distinct role of individuals, communities, and groups in explanations of scientific development.

There is also a more pragmatic argument for adopting an explanatory model like that (not necessarily the list of questions presented, but the general outline they offer), which is that of better understanding what methodologies are useful for explaining an event like a scientific controversy.

For questions referring to individuals, for instance, qualitative research and case studies seem the right choice. In order to explain scientists' actions, we need to analyze where, who they worked with, what experiments and investigations they performed, the sort of problems they were trying to answer, and the context surrounding them.

When dealing with questions involving groups and communities, however, other 
methodologies can be more suitable. For example, since communities are distinguished from groups by their social character, then we should pay attention to things such as where scientists work, who they talk to, or what conferences they go to, as to determine the different communities. Thus, to describe communities and their changes over time, as well as to determine when disagreement emerges and when consensus is again established, we can use techniques such as network analyses (e.g., Wray 2018; Bornmann et al. 2020) and agent-based models (e.g., De Langhe 2017; 2018).

Another valuable methodological resource for identifying a community is scientific literature - the articles, books, reports produced by scientists as part of their research. In SSR, Kuhn had already suggested that "a shift in the distribution of the technical literature cited in the footnotes to research reports [...] ought to be studied as a possible index to the occurrence of revolutions" (1962, p.xliii). Particularly, that material could be used to identify the alterations in consensus and dissensus that communities go through.

Scientific literature is also a valuable source of information for investigating the similarities in behavior which characterize groups. Since groups are defined as sets of scientists with similar preferences but without clear institutional or formal ties, the things they say, instead of where or to whom they say, could work in highlighting these clusters inside the community. For that task, natural language processing can be particularly useful.

The idea is that with natural language processing, we could identify theoretical compromises shared by some scientists which have not been materialized into formal ties or social patterns. That could be particularly helpful for picking out groups in periods of consensus, when their role is still incipient and not readily visible - e.g., Kuhn's pre-paradigmatic and normal science periods.

Among the methods in natural language processing adequate to that task, we could cite sentiment analysis and topic model: the first points to favorable or unfavorable evaluations of a subject (a theory, for example); the second one finds $k$ probabilistic distributions of words, that can be thought of as $k$ abstract "topics" (which could indicate, for example, that some groups of scientists approach the same subject, or theory, from distinct perspectives). Recently, Malaterre et al. (2019) and Allen \& Murdock (2020) have made interesting attempts in that direction, using Latent Dirichlet allocation (also known as LDA), a popular algorithm for topic model, to the history of philosophy and to the history of science, respectively. 


\section{Conclusion}

I began this article by highlighting a tension among different kinds of concepts in Kuhn's SSR, derived from sociological, psychological, and epistemological sources. That problem, we saw, was, in fact, connected to a second, deeper one: that of understanding the role of different kinds of units of analysis - individuals, communities, and groups - in his descriptions of scientific development.

The individual scientist is the real agent in scientific controversies, producing empirical data, exploring lines of investigation, and engaging in theoretical debates. Communities (in a reductionist sense) are analytic entities used for explaining changes in consensus and dissensus - the locus of scientific change, in Kuhn's words. Lastly, there are groups of scientists with similar behavior. Those groups have an important role in accessing the causal factors that influence individuals' evaluation formulas and, for that, in helping to explain gradual scientific changes.

Next, these different categories were organized in an explanatory model for the resolution of scientific discoveries. Then, having shown the relation between each one of these units, we could see the place and function of sociological, psychological, and epistemological concepts for understanding scientific development - the question with which this article began.

To conclude, Kuhn's appeal to concepts from different disciplines can be construed as more than a case of interdisciplinarity. The problems addressed by him are not properly the subject of psychology, sociology, or (traditional) epistemology. Instead, they belong more to a distinct and relatively new field, one that partly touches these more traditional disciplines, but differs from them in its goal: social epistemology - the attempt "to understand how the social dimensions of science contribute to the success of science" (Wray 2011, p.171). It is by virtue of his concern for social epistemology that Kuhn resorts to multiple disciplines. I hope that, by discussing the different units of analysis employed by him and their role in his explanations of scientific development, this article can contribute to an understanding of Kuhn's social epistemology, as well as to an understanding of how to explain controversies in science.

\section{References}

Abbot, A. 2016. Structure as Cited, Structure as Read. In: R. J. Richards; L. Daston (eds.) Kuhn's Structure of Scientific Revolutions at Fifty: Reflections on a Science Classic, pp.16781. Chicago University Press: Chicago.

Allen, C.; Murdock, J. 2020. LDA Topic Modeling: Contexts for the History \& Philosophy of Science. In: G. Ramsey (ed.) The Dynamics of Science: Computational Frontiers in History and Philosophy of Science. Pittsburgh University Press. 
Alvarez, M. 2018. Reasons for Action, Acting for Reasons, and Rationality. Synthese 195(8): 3293-310.

Barnes, B.; Bloor, D. 1982. Relativism, Rationalism and the Sociology of Knowledge. In: M. Hollis; S. Lukes (eds.) Rationality and Relativism. Blackwell.

Bloor, D. 1991. Knowledge and social imagery. University of Chicago Press.

Bornmann, L.; Wray, K. B.; Haunschild, R. 2020. Citation concept analysis (CCA): a new form of citation analysis revealing the usefulness of concepts for other researchers illustrated by exemplary case studies including classic books by Thomas S. Kuhn and Karl R. Popper. Scientometrics 122: 1051-74.

D'agostino, F. 2010. Naturalizing Epistemology: Thomas Kuhn and the 'Essential Tension'. Palgrave Macmillan.

D'Agostino, F. 2019a. Growth of Knowledge: Dual Institutionalization of Disciplines and Brokerage. Synthese. https://doi.org/10.1007/s11229-019-02335-1

D'Agostino, F. 2019b. The Situational Logic of Disciplinary Scholarship. In: R. Sassower; N. Laor (eds.) The Impact of Critical Rationalism: Expanding the Popperian Legacy through the Works of Ian C. Jarvie, pp.45-58. Palgrave Macmillan.

De Langhe, R. 2017. Towards the Discovery of Scientific Revolutions in Scientometric Data. Scientometrics 110(1): 505-19.

De Langhe, R. 2018. An Agent-Based Model of Thomas Kuhn's The Structure of Scientific Revolutions. Historical Social Research 43(1): 28-47.

Elster, J. 1985. Making Sense of Marx: Studies in Marxism and Social Theory. Cambridge University Press.

Garfield, E. 1987. A Different Sort of Great-Books list: The 50 Twentieth-Century Works Most Cited in the Arts Humanities Citation Index, 1976-1983. Current Contents 16: 3-7.

Golinski, J. 2008. Chemistry. In: R. Porter (ed.) The Cambridge History of Science, vol. 4 Eighteenth-Century Science, pp.375-96. Cambridge University Press.

Hacking, I. 2012. Introductory Essay. In: The Structure of Scientific Revolutions. 2. Ed. University of Chicago Press.

Hogan, J. 1991. Profile: Reluctant Revolutionary: Thomas S. Kuhn Unleashed 'Paradigm' on the World. Scientific American 40.

Hufbauer, K. 2012. From student of physics to historian of science: TS Kuhn's education and early career, 1940-1958. Physics in Perspective 14(4): 421-70.

Hull, D. L.; Tessner, P. D.; Diamond, A. M. 1978. Planck's principle. Science 202(4369): 71723.

Jarvie, I. C. 1998. Situational Logic and its Reception. Philosophy of the Social Sciences 28(3): 365-80.

Kaiser, D. 2016. Thomas Kuhn and the Psychology of Scientific Revolutions. In: R. Richards; L. Daston (eds.) Kuhns Structure of Scientific Revolutions at Fifty: Reflections on a Science Classic, pp.71-95. Chicago University Press.

Kincaid, H. 1986. Reduction, Explanation, and Individualism. Philosophy of Science 53(4): 492-513.

King, G.; Keohane, R. O.; Verba, S. 1994. Designing social inquiry: Scientific inference in qualitative research. Princeton University Press.

Kuhn, T. S. 1959[1977]. The Essential Tension: Tradition and Innovation in Scientific Research. In: The Essential Tension: Selected Studies in Scientific Tradition and Change. Chi- 
cago University Press.

Kuhn, T. S. 1962[2012]. The Structure of Scientific Revolutions. 2. Ed. University of Chicago Press.

Kuhn, T. S. 1970[2000]. Postscript. In: The Structure of Scientific Revolutions. 2. Ed. University of Chicago Press.

Kuhn, T. S. 1977. Objectivity, Value Judgment, and Theory Choice. In: The Essential Tension: Selected Studies in Scientific Tradition and Change. University of Chicago Press.

Kuhn, T. S. 1989[2000]. Possible Worlds in History of Science. In: The Road Since Structure. University of Chicago Press.

Kuhn, T. S. 1991[2000]. The Road Science Structure. In: The Road Since Structure. University of Chicago Press.

Kuhn, T. S. 1992[2000]. The Trouble with the Historical Philosophy of Science. In: The Road Science Structure. University of Chicago Press.

Kuhn, T. S. 1993[2000]. Afterwords. In: The Road Since Structure. University of Chicago Press.

Lakatos, I.; Musgrave, A. 1970. Criticism and the Growth of Knowledge. Cambridge University Press.

Latour, B. 1987. Science in action: How to follow scientists and engineers through society. Harvard University Press.

Levin, S. G.; Stephan, P. E.; Walker, M. B. 1995. Planck's principle revisited: A note. Social Studies of Science 25(2): 275-83.

Malaterre, C.; Chartier, J.-F; Pulizzotto, D. 2019. What is this Thing Called Philosophy of Science? A Computational Topic-Modeling Perspective, 1934-2015. HOPOS 9(2): 21549.

Merton, R. K. 1979. The Sociology of Science: An Episodic Memoir. Southern Illinois University Press.

Mitrović, B. 2017. Is Multiple Realizability a Valid Argument Against Methodological Individualism? Philosophy of the Social Sciences 47(1): 28-43.

Mody, C.; Kaiser, D. 2008. Scientific Training and the Creation of Scientific Knowledge. In: E. J. Hackett; O. Amsterdamska; M. E. Lynch; J. Wajcman (eds.) The Handbook of Science and Technology Studies, pp.377-402. 3rd. ed. University of Chicago Press.

Morgan, S. L.; Winship, C. 2015. Counterfactuals and Causal Inference. Cambridge University Press.

Pirozelli, P. 2019. Thomas Kuhn's Theory of Rationality. Manuscrito 42(3): 1-46.

Politi, V. 2018. Scientific revolutions, specialization and the discovery of the structure of DNA: toward a new picture of the development of the sciences. Synthese 195: 2267-93.

Sawyer, R. K. 2002. Nonreductive Individualism: Part I: Supervenience and Wild Disjunction. Philosophy of the Social Sciences 32(4): 537-59.

Shapin, S. 2015. Kuhn's Structure: A Moment in Modern Naturalism. In: W. J. Devlin; A. Bokulich (eds.) Kuhn's Structure of Scientific Revolutions-50 Years On. Springer.

Wray, K. B. 2011. Kuhn's Evolutionary Social Epistemology. Cambridge University Press.

Wray, K. B. 2018. A note on measuring normal science. Scientometrics 117(1): 647-50. 


\section{Notes}

${ }^{1}$ Among other things, SSR had sold more than one million copies in sixteen languages by the early 1990s (Hogan 1991), and was the most cited book in the arts and humanities between 1976 to 1983 (Garfield 1987). For more information about the reception and success of the book, see Hacking (2012).

${ }^{2}$ Which can be seen, for example, in the discussion that took place at the International Colloquium in the Philosophy of Science (Lakatos \& Musgrave 1970).

${ }^{3}$ The influence on the constructivist currents in sociology of science is explicit in authors as Bloor (1991), Barnes \& Bloor (1982), and Latour (1987). SSR also had a huge impact in mainstream Sociology, as can be seen by Merton's admiration for Kuhn's work (1979) (who was none less than the founder of that discipline). For a fuller account of the book's reception, see Kaiser (2016) and Abbot (2016).

${ }^{4}$ Curiously, as pointed by one of the reviewers to this paper, the distinction between individuals and communities was clearly distinguished by Kuhn in "The Essential Tension" (1959), an article written a few years before SSR. After stating that "the successful scientists must simultaneously display the characteristics of the traditionalist and of the iconoclast", Kuhn explains that "strictly speaking, it is the professional rather than the individual that must display both these characteristics simultaneously". He then proceeds on to say that "in a fuller account of the ground covered in this paper that distinction between individual and group characteristics would be basic" (p.228, n.2).

${ }^{5}$ There would still be a problem as regards the ontological status of communities, but this has no direct implications for the discussion here.

${ }^{6}$ Contrary to Politi (2018), I do not think that, for Kuhn, "the scientific community is both the agent and the locus of scientific activity" (p.2271). Communities are indeed the locus of scientific activity - where consensus and dissensus occur and research tradition develop but only individuals are, in a strict sense, agents.

${ }^{7}$ There is no robust evidence that Planck's principle is actually true (Hull et al., 1978; Levin et al., 1995). That has no implication, however, for understanding the role of groups in Kuhn's model of science.

${ }^{8}$ It would still be possible to distinguish individuals form communities and groups, even if we adopted a non-reductionist attitude, assuming, for example, that the last two are emergent properties. That would, certainly, demand a more complex argumentation, which would just divert us from the relevant point at stake (that individuals are different from communities and groups, which although is not free of theoretical assumptions, is, I think, acceptable by most people). For this, I preferred to use the reductionist view, which seems to me more intuitive. It is also the version that I use in the next section, when proposing a model for explaining scientific controversies.

${ }^{9}$ Here, I assume a methodological individualism in which communities are no more than abbreviations for multiple individuals in interaction; what I previously called community $r$. Besides personally preferring that position, it makes the role of each of the different categories clearer. Anyway, such a reductionist stance, I think, is not essential to the explanation's general outline. 


\section{Acknowledgments}

I am grateful to two anonymous referees for their criticisms and suggestions. Professor Fred D'Agostino has also provided valuable feedback on a first draft of this paper. 